\title{
Manganese Toxicity Upon Overexposure: a Decade in Review
}

\author{
Stefanie L. O'Neal ${ }^{1}$ - Wei Zheng ${ }^{1}$
}

Published online: 1 July 2015

(C) Springer International Publishing AG 2015

\begin{abstract}
Exposure to manganese (Mn) causes clinical signs and symptoms resembling, but not identical to, Parkinson's disease. Since our last review on this subject in 2004, the past decade has been a thriving period in the history of Mn research. This report provides a comprehensive review on new knowledge gained in the Mn research field. Emerging data suggest that beyond traditionally recognized occupational manganism, Mn exposures and the ensuing toxicities occur in a variety of environmental settings, nutritional sources, contaminated foods, infant formulas, and water, soil, and air with natural or man-made contaminations. Upon fast absorption into the body via oral and inhalation exposures, Mn has a relatively short half-life in blood, yet fairly long half-lives in tissues. Recent data suggest $\mathrm{Mn}$ accumulates substantially in bone, with a half-life of about 8-9 years expected in human bones. Mn toxicity has been associated with dopaminergic dysfunction by recent neurochemical analyses and synchrotron X-ray fluorescent imaging studies. Evidence from humans indicates that individual factors such as age, gender, ethnicity, genetics, and pre-existing medical conditions can have profound impacts on $\mathrm{Mn}$ toxicities. In addition to body fluid-based biomarkers, new approaches in searching biomarkers of Mn exposure include Mn levels in toenails, noninvasive measurement of $\mathrm{Mn}$ in bone, and functional alteration assessments. Comments and recommendations are also provided with regard to the diagnosis of $\mathrm{Mn}$ intoxication and
\end{abstract}

This article is part of the Topical Collection on Metals and Health

Wei Zheng

wzheng@purdue.edu

1 School of Health Sciences, Purdue University, 550 Stadium Mall Drive, Room 1173, West Lafayette, IN 47907, USA clinical intervention. Finally, several hot and promising research areas in the next decade are discussed.

Keywords Manganese - Biomarker · Toxicity · Environment · Parkinsonism

$\begin{array}{ll}\text { Abbreviations } \\ \mathrm{Cu} & \text { Copper } \\ \text { DMT1 } & \text { Divalent metal transporter-1 } \\ \text { EDTA } & \text { Ethylenediaminetetraacetic acid } \\ \text { Fe } & \text { Iron } \\ \text { MMT } & \text { Methylcyclopentadienyl manganese tricarbonyl } \\ \text { Mn } & \text { Manganese } \\ \text { PAS } & \text { Para-aminosalicylic acid } \\ \text { PI } & \text { Pallidal index } \\ \text { XRF } & \text { X-ray fluorescence }\end{array}$

\section{Introduction}

Manganese (Mn) is the 12th most abundant element on the earth [1]. As a transition metal, Mn exists in more than five valence states, with a majority as $\mathrm{Mn}^{2+}$ or $\mathrm{Mn}^{3+}$ [2]. In the environment, it is found mainly in its oxidized chemical forms, as $\mathrm{MnO}_{2}$ or $\mathrm{Mn}_{3} \mathrm{O}_{4}$ [3]. $\mathrm{Mn}$ is essential to human health, acting as a co-factor in the active centers of various enzymes, and is required for normal development, maintenance of nerve and immune cell functions, and regulation of blood sugar and vitamins, among other functions [4-6]. Overexposure to this metal, however, can be toxic to many organ systems and across different life stages.

In 2004, we summarized the impact of Mn exposure on general human health [6]. At the time, a majority of evidence on $\mathrm{Mn}$ intoxication came from occupational settings, because 
of high exposure levels. Over the past decade, much progress has been made in the Mn research field, from toxicokinetics to exposure assessment and from the mode of action to clinical therapeutic intervention. Recent studies from this and other laboratories have indicated that low-level occupational exposure, with air Mn concentrations at or below occupational standards, can also be detrimental. Neurochemical, neurobehavioral, and neuroendocrine changes may occur before structural damage occurs and are linked to pathogenic conditions [7-12]. In addition to the exposure level and duration, there are other unique factors, such as age, gender, ethnicity, genetics, location, and pre-existing medical conditions that may contribute to Mn toxicity.

This article seeks to provide a comprehensive review of the new insights into environmental Mn exposure gained in the last decade. The current understanding of Mn toxicokinetics and its distribution in the brain by using advanced synchrotron $\mathrm{X}$-ray fluorescence imaging technique will be first introduced. The advantage and disadvantage of using bone Mn levels as a potential indicator for Mn body burden will be addressed. This will be followed by a general review of the updated knowledge on Mn systemic toxicities including effects on the brain, the liver, and the cardiovascular system. Finally, comments and recommendations will be made with regard to the diagnosis of Mn intoxication and clinical intervention.

\section{Absorption, Distribution, and Elimination}

The highest concentrations of $\mathrm{Mn}$ are present in the bone, liver, kidney, pancreas, and adrenal and pituitary glands [13]. The normal concentration of Mn in human tissues is
$1 \mathrm{mg} / \mathrm{kg}$ in the bone [14], $1.04 \mathrm{mg} / \mathrm{kg}$ in the pancreas, and $0.98 \mathrm{mg} / \mathrm{kg}$ in the kidney cortex [13]. The normal blood Mn concentrations range from 4 to $15 \mu \mathrm{g} / \mathrm{L}$ in humans [15]. A recent survey among the general Chinese population suggests that women have a higher blood Mn level than men ( 28.6\%) [16]. In the body, Mn is transported and regulated by several macromolecules (Table 1).

\section{Chemical Species of Mn in Body Fluids}

In the human body, Mn exists primarily in two oxidized states, i.e., $\mathrm{Mn}^{2+}$ and $\mathrm{Mn}^{3+}$. $\mathrm{Mn}^{2+}$ species in the blood are bound to high-molecular-mass fractions, such as albumin and $\beta$ globulin as hydrated ions, and also in complexes with bicarbonate, citrate, and other low-molecular-mass species [32, 33]. Nearly $100 \%$ of $\mathrm{Mn}^{3+}$ species are bound to transferrin (Tf), to form a more stable complex [34]. Mn molecules in tissues such as the liver, kidney, pancreas, bone, and brain exist primarily as $\mathrm{Mn}^{2+}[6]$.

In the cerebrospinal fluid, $\mathrm{Mn}^{2+}$ ions are bound to lowmolecular-weight compounds, such as Mn citrate [34]. This form is thus thought to be transported by a citrate transporter [35]. More evidence, however, suggests that $\mathrm{Mn}^{2+}$ species are transported mainly by the divalent metal transporter DMT1 as the primary influx route to the brain, although the other transporting proteins such as ZIP8 are suggested to mediate $\mathrm{Mn}$ transport into the brain $[4,36]$. Evidence in literature has also suggested that $\mathrm{Mn}^{2+}$ can enter the brain by store-operated calcium channels, but the extent of this route is much less than that of transporter-mediated transports [35]. The other Mn species entering the brain is $\mathrm{Mn}^{3+}$, which is complexed with

Table 1 Proteins involving in maintaining Mn homeostasis

\begin{tabular}{|c|c|c|c|}
\hline Name and abbreviation & Mn species bound & Function & Reference \\
\hline Divalent metal transporter (DMT1/SLC11A2) & Mn (II) & Mn uptake & {$[17]$} \\
\hline Transferrin (Tf) & Mn (III) & Mn uptake & [18] \\
\hline Tf receptor (TfR) & Mn (III) & Mn uptake & {$[18,19]$} \\
\hline Citrate & Mn (II) & Mn uptake & {$[20]$} \\
\hline ZIP8 (SLC39A8) & Mn (II) & Mn uptake & {$[21]$} \\
\hline ZIP14 (SLC39A14) & Mn (II) & Mn uptake & {$[22]$} \\
\hline Voltage regulated calcium channels & $?$ & Mn uptake & {$[23]$} \\
\hline Ionotropic glutamate receptor-calcium channels & $?$ & Mn uptake & {$[24]$} \\
\hline Store-operated calcium channels & Mn (II) & Mn uptake & {$[25]$} \\
\hline SLC30A10 & $?$ & Mn efflux & {$[26]$} \\
\hline Ferroportin (SLC40A1) & Mn (II) & Mn efflux & {$[27]$} \\
\hline Metallothionein & $?$ & storage protein & {$[28]$} \\
\hline Iron regulatory protein-1 (IRP1) & Mn (II) & Mn can replace the 4th $\mathrm{Fe}$ in the $4 \mathrm{Fe}-4 \mathrm{~S}$ Enzyme action center & {$[29]$} \\
\hline Ceruloplasmin & Mn (II) & Potentially oxidizes Mn (II) to Mn (III) & {$[30]$} \\
\hline Superoxide dismutase & Mn (II) & Oscillates between Mn (II) and Mn (III) species & {$[31]$} \\
\hline
\end{tabular}

Question mark indicates uncertainty 
transferrin and via the transferrin receptor (TfR)-mediated process (Table 1) [19].

\section{Absorption}

The main route of $\mathrm{Mn}$ absorption is through the gastrointestinal tract, but the absorption also occurs in the lungs following inhalation exposure [1]. The intravenous injection of illegal narcotics containing Mn has recently provided a third route of exposure [37].

Inhalation exposure to airborne $\mathrm{Mn}$ is common among welders and smelters [38-40]. Inhaled Mn can bypass the liver to enter the blood stream; from there, it can enter the brain via the olfactory tract bypassing the blood-brain barrier [41, 42]. Studies in rats demonstrate that $\mathrm{Mn}$ is rapidly transported along the evolutionarily conserved olfactory pathway and is present within the olfactory bulb $8-48 \mathrm{~h}$ after exposure. It is believed that the trigeminal nerve may also play a role in delivering Mn from the nasal cavity to the brain [38, 42, 43].

Oral exposure is another common route of exposure. $\mathrm{Mn}$ is required in small quantities obtained through dietary intake. The average daily intake for many Western diets is between 2.3 and $8.8 \mathrm{mg}$ [44], but this can be much higher. Consumption of food or water contaminated with high levels of Mn has toxic consequences [45]. For example, the water supply in Bangladesh is contaminated with Mn up to $2.0 \mathrm{mg} / \mathrm{L}$ [46], which is fourfold higher than the WHO standard for drinking water of $400 \mu \mathrm{g} / \mathrm{L}$ [47]. Studies among school children suggest that increased levels of $\mathrm{Mn}$ in the drinking water in Bangladesh area are inversely associated with students' achievement scores in mathematics [48]. High levels of Mn in drinking water in Canada have been found to lead to significantly higher levels of $\mathrm{Mn}$ in hair samples in school-age children. The increased hair Mn concentrations are significantly associated with increased hyperactive behaviors [49], impaired cognitive development [47], and a decrease in IQ points [50]. In Italy, school-age children living near a ferroalloy plant have been found to have significant impairment of motor coordination, hand dexterity, and odor identification after exposure to excess levels of Mn in soils [51]. It is alarming that the high $\mathrm{Mn}$ concentration in drinking water is not solely a public health issue unique to developing countries; approximately $5.2 \%$ of the 2167 wells surveyed across the USA exceeded the health benchmark of $300 \mu \mathrm{g} / \mathrm{L}$ [52].

Another potential source of oral exposure is from consuming milk- or soy-based infant formulas, which contain high levels of Mn. The FDA sets a minimum nutritional requirement of $5 \mu \mathrm{g} / 100 \mathrm{kcal}$ for the amount of Mn infant formulas must contain; yet, there is no maximum established. According to the Institute of Medicine's recommendation, infants can consume about $3 \mu \mathrm{g} \mathrm{Mn} /$ day for $0-6$ months. Infants can drink up to a liter of formula a day. When formula is prepared according to the manufacturer's instructions, infants could consume from 32 to $51 \mu \mathrm{g}$ of Mn per day, far exceeding the aforementioned recommendation. Soy-based formulas contain more Mn than cow-based formulas, and both contain much more Mn than does human breast milk [53]. Since only a small percentage of $\mathrm{Mn}$ is eliminated in human breast milk and because breastfed babies consume smaller volumes of milk than do bottle-fed babies at each feeding [54], feeding breast milk is considered much safer than feeding formulas to infants. It is also known that the concentrations of $\mathrm{Mn}$ in a mother's milk decrease as lactation progresses. Laboratory testing has shown that babies who drink formulas had higher concentrations of $\mathrm{Mn}$ in hair samples than those who were breastfed [55]. The higher level of dietary Mn intake has been suggested to be associated with the risk of developing the attention deficit hyperactivity disorder (ADHD) [56].

Recently, cases of Mn-induced Parkinsonism have been reported among intravenous ephedrone abusers in Estonia, Turkey, Eastern Europe, the Baltic States, and Canada [19, 57]. $\mathrm{Mn}$ is added to the drug cocktail as the oxidizing agent potassium permanganate; the final $\mathrm{Mn}$ concentration can be as high as $0.6 \mathrm{~g} / \mathrm{L}$. Multiple injections per day can result in doses ranging from 60 to $180 \mathrm{mg} /$ day by intravenous administration. This amount far exceeds the $0.1 \mathrm{mg} \mathrm{Mn} /$ day recommended as an intravenous supplement. Continued uses can lead to elevated Mn concentrations in blood and urine, and patients have signs and symptoms such as impaired speech, cockwalk, bradykinesia, and ataxia [37]. Even after cessation of ephedrone use, some of the motor symptoms continue to progress [37, 57].

\section{Distribution}

Once Mn enters the circulation from either the small intestine or lung, it accumulates mainly in the liver $(1.2-1.3 \mathrm{mg} / \mathrm{kg})$, brain $(0.15-0.46 \mathrm{mg} / \mathrm{kg})$, and bone ( $1 \mathrm{mg} / \mathrm{kg}$ up to $43 \%$ ) [13, $14,58,59]$. Mn is detectable in the cerebrospinal fluid before it is detectable in the brain parenchyma, suggesting that it is transported through the choroid plexus [60].

The brain is the target organ of Mn toxicity. In human subjects exposed to $\mathrm{Mn}$ in the work place, magnetic resonance imaging (MRI) studies have established higher levels of Mn accumulation in the globus pallidus than in other brain structures [9, 61]. Rapid advancement in synchrotron X-ray fluorescence (XRF) imaging technique has made it possible to illustrate the Mn distribution pattern in the brain. In rat brains, Mn accumulates with the highest concentration in the globus pallidus, followed by the substantia nigra pars compacta, thalamus, caudate putamen, axon bundles, and cortex [62]. While the hippocampus does not accumulate more Mn than other regions in control animals, Mn exposure in fact increases hippocampal $\mathrm{Mn}$ to the same level as those in the substantia nigra pars compacta and thalamus. Thus, it appears that the hippocampus has an equal susceptibility to Mn toxicity. Moreover, 
the XRF data show that Mn tends to accumulate in brain regions that also have a high iron $(\mathrm{Fe})$ concentration [63].

Mn concentrations are thought to be greater in astrocytes than in neurons [57]. However, the XRF data from single cells show a diffuse Mn distribution pattern within cells of the hippocampus CA3, which are likely neurons. Since only $30 \%$ of astrocytes are saturated after Mn exposure, it seems unlikely that astrocytes serve as the primary target of $\mathrm{Mn}$ accumulation in the rodent model [63].

In addition to the brain and liver, $\mathrm{Mn}$ accumulates extensively in the human bone under normal physiological conditions [64]. By examining the human bone collected during autopsy, it is estimated that bone contains about $40 \%$ of the total body burden of Mn [65]. Our recent study in rats has shown that after subchronic oral exposure to $\mathrm{Mn}, \mathrm{Mn}$ accumulates in the femur, tibia, humerus, and parietal bone with accumulation reaching steady-state concentrations after 6 weeks of dose administration [66••].

$\mathrm{Mn}$ is intracellularly distributed in red blood cells due to the presence of transferrin receptor and DMT1 in this cell type [6, 61]. Inside of the cell, Mn acts on the mitochondria and disrupts energy production [67-69]. But mitochondria may not be the major intracellular organelles where $\mathrm{Mn}$ ions accumulate. Morello and colleagues used electron spectroscopy imaging and demonstrated that the highest concentrations of $\mathrm{Mn}$ were present in the heterochromatin and the nucleolus, followed by a lower concentration of $\mathrm{Mn}$ in the cytoplasm, with the lowest levels in the mitochondria. After chronic Mn exposure, the highest levels of $\mathrm{Mn}$ were observed in the mitochondria [70].

In a comparative in vitro study utilizing choroidal epithelial Z310 cells, rat brain endothelial RBE4 cells, and dopaminergic N27 and PC12 cell lines, cells were fractionated to separate the nuclei and mitochondria. After Mn exposure, the highest levels of accumulation were found in the PC12 and N27 neuronal cell types compared with the non-neuronal brain barrier Z310 and RBE4 cell types. Most Mn was present within the nuclei, which was true for all four cell lines; only limited accumulation was observed in the mitochondria $(<0.5 \%)$ and microsomes $(<2.5 \%)$ [71]. Nonetheless, the profound Mn toxicity on mitochondrial function should not be underestimated.

\section{Elimination}

The primary route of Mn elimination is via the fecal hepatobiliary excretion with limited urinary excretion [72]. Some Mn-containing molecules such as Mn-DPDP and Mn nanoparticles show different elimination patterns from the metal Mn [73-75]. Mn is also eliminated in milk as mentioned above. However, this route of elimination does not constitute a major route of Mn excretion. Similarly, very low levels of Mn are excreted in sweat [76].
In the brain parenchyma, $\mathrm{Mn}$ rapidly accumulates in the brain structures such as the superior and inferior colliculi, amygdala, stria terminalis, hippocampus, and globus pallidus. The half-lives of $\mathrm{Mn}$ in these tissues are about 5-7 days, with the longest retention in the periaqueductal gray, amygdala, and entorhinal cortex [77]. The elimination rate from brain tissue is expected to be slower than from either liver or kidney. In the rat, the half-lives of 16 brain regions are between 52 and 74 days [6].

In a recent study in rats, we administered Mn by oral gavage at $50 \mathrm{mg} / \mathrm{kg}$ for 10 weeks. It was interesting to observe that by the fourth week of dose administration, $\mathrm{Mn}$ in blood reached the steady-state concentration, which was maintained for the duration of the study. Mn concentrations in the cerebrospinal fluid, however, continued to increase even at the eight week. It is possible that a slow elimination of $\mathrm{Mn}$ from the cerebrospinal fluid may contribute to the high level of $\mathrm{Mn}$ in the brain $[66 \cdot \bullet]$. It is also possible that a redistribution of $\mathrm{Mn}$ from the bone compartment to the central nervous system may account, at least partially, for the high level of $\mathrm{Mn}$ in the cerebrospinal fluid. By studying the elimination rate constant and half-lives, our data revealed that the half-lives of $\mathrm{Mn}$ in various rat bones were between 77 and 690 days with an average of 143 days for the whole skeleton [66••]. A comparative study between human and rat estimates that every 16.7 days of a rat's life is equivalent to one human year [78]. By using this figure, the range of Mn half-lives in the rat skeleton is estimated approximately $4.6-41.3$ years in humans with an average half-life of 8.6 years for humans [66••].

\section{Human Exposure to Mn}

The primary source of clinically identified Mn intoxication is due to occupational exposure. Neurotoxicity due to inhalation exposure to airborne $\mathrm{Mn}$ has been reported in miners in $\mathrm{Mn}$ dioxide mines [79], workers in dry-cell battery factories [80], smelters $[7,8,39,61,81]$, and steel manufacturing workers or welders [82-86]. Our own studies on 3200 welders in 142 factories in the metropolitan area of Beijing reveal a significant correlation between airborne Mn level and manganism among welders with an estimated exposure dosages (calculated by the weight of welding rods) of 5-20 kg (containing $0.3-$ $6 \% \mathrm{Mn}$ ) per working day per person $[6,87]$.

There are many environmental sources of $\mathrm{Mn}$, which include eroded rocks, soils, and decomposed plants. Human activities expose individuals to additional sources containing $\mathrm{Mn}$, including the fungicides, maneb and mancozeb, medical imaging contrast agents, and water purification agents. Additionally, several countries including the USA, Canada, Argentina, Australia, Bulgaria, France, Russia, New Zealand, China, and the European Union have approved use of the fuel additive methylcyclopentadienyl manganese 
tricarbonyl (MMT) [1, 34]. Combustion of gasoline containing MMT releases Mn phosphates, sulfates, and oxides into the air, especially where there is high traffic density releasing particles within the respirable size range $[1,88]$. Mncontaining emissions contaminate soil, dust, and plants near roadways, which introduces additional $\mathrm{Mn}$ to the environment [89]. Recent projections of MMT use indicate the average person's Mn absorption may increase by several percent. It should be noted that this is an estimated average level of exposure; therefore, some people may be exposed more substantially than others [88].

Ultimately, Mn from these various sources ends up in the water supply. As Mn filters down through the soil, it is reduced to the more soluble $\mathrm{Mn}^{2+}$ form where it can easily make its way into the ground and surface waters. Ground water has the highest concentration of $\mathrm{Mn}$, but surface water and water near mining operations contain high levels of $\mathrm{Mn}$ as well [1].

\section{Manganese-Induced Toxicities}

\section{Mn-Induced Neurotoxicity}

Cumulative evidence has established that Mn exposure induces signs and symptoms similar but not identical to Parkinson's disease [39, 57, 90-93]. A study on six manganism patients who were occupationally exposed to $\mathrm{Mn}$ as welders or smelters in Guangxi, China, suggested that Mn exposure led to clinical manifestations of Parkinsonian syndromes with considerable variations. One patient who had a classic presynaptic syndrome and responded to LDOPA was clearly Mn intoxicated. Moreover, a case with a 25-year Mn exposure showed a syndrome of Parkinsonism at an early age with MRI abnormalities bilaterally in the globus pallidus $[92,93]$. Thus, these observations support an overlap in syndromes between Mn-induced movement disorder and Parkinson's disease [90-93].

While the linkage between manganism and Parkinson's disease is noteworthy, animal studies suggest that dopaminergic neurons in the substantia nigra and their terminals in the striatum, which are selectively lesioned in Parkinson's disease, remain intact after Mn intoxication [5]. Thus, changes in neurotransmission, rather than a massive dopamine neuronal cell loss, likely underlie behavioral observations.

Reports of Mn exposure altering neurotransmitter and metabolite levels have been published in literature [94, 95•]. To investigate the changes in dopamine, dopamine metabolites, such as 3,4-dihydroxyphenylacetic acid (DOPAC) and homovanillic acid (HVA), and GABA, in rat brain after Mn exposure, we exposed rats subchronically with intraperitoneal injections of $15 \mathrm{mg} \mathrm{Mn} / \mathrm{kg}$ for 4 weeks. Data showed a significantly increased dopamine level in the striatum; this increase was accompanied by increased levels of DOPAC and HVA in the same region. Interestingly, the HVA level was also increased in the substantia nigra and hippocampus, indicating an increased dopamine turnover in the substantia nigra, which is the pathogenic region in Parkinson's disease. In the same animals, a significant increase of GABA in the hippocampus was also evident, although no structural abnormalities appeared to be identifiable in the striatum, substantia nigra, or hippocampus in response to the low-level subchronic Mn exposure [96]. In agreement with our report, Vorhees and colleagues recently showed that $\mathrm{Mn}$ exposure increased striatal dopamine and HVA concentrations compared to controls. They also observed an increased norepinephrine in the striatum and increased dopamine, NE, and serotonin levels in the hippocampus. By utilizing various ages of animals, these investigators reported that $\mathrm{Mn}$ exposure altered monoamines as a function of age [97].

In a human study utilizing magnetic resonance imaging and spectroscopy (MRI/S) to investigate changes in neurochemistry of smelting workers, increases in GABA and decreases in myo-inositol were seen in the thalamus. Changes in thalamic GABA were associated with reduced fine motor performance as assessed by the Purdue Pegboard test [98].

Recent investigation of Mn neurotoxicity has also extended to the field of adult neurogenesis, which takes place in two critical niche areas in the brain, i.e., the subventricular zone and the subgranular zone. Application of the synchrotron Xray fluorescent imaging technique to study brain distribution of copper $(\mathrm{Cu})$ and $\mathrm{Fe}$ with or without $\mathrm{Mn}$ exposure has led to an unexpected discovery that $\mathrm{Cu}$ accumulated in the subventricular zone extraordinarily higher than in any other brain regions [99]. Further in vivo studies revealed that subchronic Mn exposure in rats greatly increased the cell proliferation in the subventricular zone and the associated rostral migratory stream, but significantly reduced the $\mathrm{Cu}$ levels in the subventricular zone [100•]. These observations raise interesting questions as to what is the role of $\mathrm{Cu}$ in adult neurogenesis and how $\mathrm{Mn}$, by interacting with $\mathrm{Cu}$ for its transport, intracellular storage, and trafficking, may alter the normal neuronal repair process, which may contribute to nonmotor symptoms in Mn-induced Parkinsonian disorder.

Kikuchihara and colleagues further confirmed that oral Mn exposure resulted in reduced numbers of local Pvalb $(+)$ GABAergic interneurons in the other neurogenic niche, the subgranular zone of the dentate gyrus in the hippocampus of mice [101]. Similar to the data published by our group, Kikuchihara's group also observed a reduced $\mathrm{Cu}$ level in the subgranular zone after Mn exposure, although differences between these two studies in animal species, exposure route, and duration are evident. Since $\mathrm{Mn}$ exposure results in reduced $\mathrm{Cu}$ levels in both neurogenic niches, these two independent studies may suggest a similar molecular mechanism underlying Mn neuropathology. 


\section{Mn-Induced Cardiovascular Toxicity}

Despite a lack of epidemiological evidence, animal and human evidences support the view that Mn exposure significantly alters cardiovascular function. Intravenous injection of $\mathrm{Mn}$ at a high dose $(5-10 \mathrm{mg} \mathrm{Mn} / \mathrm{kg}$ ) caused a decreased heart rate and blood pressure and increased P-R and QRS intervals [102]. In perfused rat hearts, an MRI contrast agent MnDPDP had similar but reduced effects on cardiac function as compared with $\mathrm{Mn}^{2+}$ [103]. Limited data from human populations are available, but it somewhat contradicts the data from animal studies. As opposed to the decreased blood pressure and heart rate observed in animal studies, smelters showed significantly faster heart rates than control subjects. Additionally, while animal studies showed increased P-R intervals, the reverse was true for the smelters, although the QRS and T waves were wider and elevated in both male and female smelters compared to controls [68].

Overexposure to the MRI enhancer Mn-DPDP causes flushed face and the head and ears feeling hot. Postural hypotension has also been observed in Mn-DPDP-overdosed patients [68]. Even when cardiac function is not significantly altered, the mean diastolic blood pressure can be significantly lower, while and diastolic hypotension can be significantly higher, in Mn-exposed workers as compared to control subjects. Workers with the highest level of exposure to Mn exhibit the lowest systolic blood pressure [68].

Despite differences in the levels of exposure between human and animal studies, it appears that Mn exposure inhibits myocardial contraction, dilates blood vessels, and induces hypotension, suggesting that $\mathrm{Mn}$ exposure has a significant effect on cardiac function. The exact mechanism of cardiac toxicity remains unknown; it has been shown that $\mathrm{Mn}$ has a direct effect on mitochondrial function resulting in a reduced myocardial contraction, and causes vasodilation, leading to a decreased blood pressure following acute exposure [68]. However, the research evidence on whether and how chronic low-level Mn exposure causes cardiovascular toxicities from both human and animal studies remains sparse. Future work to evaluate these effects is well warranted.

\section{Mn Exposure and Infant Mortality}

Increased Mn levels in water sources have been linked to increased infant mortality. An analysis of groundwater concentrations in North Carolina reveals that infant mortality increases by a factor of 2 per 1000 live births for every $\log$ increase in groundwater Mn concentration [104]. Hafeman et al. also report an increased mortality in the first year of life in infants in Bangladesh exposed to Mn concentrations at or above the WHO's standard of $400 \mu \mathrm{g} \mathrm{Mn} / \mathrm{L}$ compared to unexposed infants [105].

\section{Mn Toxicity and Liver Function}

Since the original report by Klaassen in 1976 describing the hepatobiliary excretion of $\mathrm{Mn}$ from the liver [72], not much work has been done to describe Mn-induced hepatotoxicity. The liver is a known storage organ for $\mathrm{Mn}$; the highest $\mathrm{Mn}$ uptake occurs in the liver, only second to brain uptake [36]. Hepatic Mn accumulation in mice intravenously injected with Mn nanoparticles persisted significantly longer than other highly perfused tissues such as kidney and spleen; however, no histopathological damage was observed [75].

Hepatobiliary excretion of Mn represents a primary route of Mn clearance from the body, accounting for $80 \%$ of $\mathrm{Mn}$ elimination. Thus, severe liver damage, owing to various chronic liver diseases, can result in an excessive accumulation of $\mathrm{Mn}$ in brain with ensuing signs and symptoms clinically called Mn hepatic encephalopathy [106]. With weakened liver function, there is also an increased risk of neurodegeneration with continued Mn exposure [107]. In those patients with chronic hepatic encephalopathy, liver transplant has proven to be effective in reducing brain Mn concentrations. When patients were re-examined 5 months after transplant, the T1weighted MRI signals in the basal ganglia were absent [106]. These data suggest that the normal liver function is essential to maintain homeostasis of $\mathrm{Mn}$ in the body, including the CNS.

\section{Mn Toxicity and Individual Susceptibility}

There are many factors that may predispose one individual to $\mathrm{Mn}$ toxicity over another. These individual factors include age, gender, ethnicity, genetics, and pre-existing medical conditions, such as chronic liver disease.

Age is a common factor which may influence an individual's susceptibility to Mn toxicity. Very young animals as well as humans have increased intestinal Mn absorption [97] and also have increased accumulations of $\mathrm{Mn}$ in the CNS [108], due to increased permeability of neuronal barriers to $\mathrm{Mn}$ [34]. The young also have a reduced biliary excretion capacity [56]. The 2011-2012 National Health and Nutrition Examination Survey (NHANES), a study of US residents, found higher Mn levels in the younger population, with the highest levels in 1year-old infants [109]. These age-related factors can increase the risk of neurotoxicity following exposure.

Alternatively, the very old are a population of special concern, because of the large number of people who develop idiopathic Parkinsonism. Brain regions such as the globus pallidus, substantia nigra, and striatum are involved in both Mn neurotoxicity and Parkinsonism; thus, it is possible that the elderly may have a subclinical pathology and could be "pushed over the edge" by increased doses of Mn [110]. For example, in one of our occupational exposure studies, we found that smelters without clinical symptoms performed significantly worse on the Purdue Pegboard test, which is a 
measure of fine motor coordination, than control subjects. The scores got worse with age, which was not unexpected as fine motor coordination declines with age. However, Mn exposure appears to exacerbate this decline [8].

Gender is another common factor which may influence an individual's susceptibility to Mn toxicity. The 2011-2012 NHANES study of US residents reported significantly higher blood Mn levels in women of all ethnicities than men. The authors suggest metabolic differences in the regulation of $\mathrm{Mn}$ between men and women may underlie the difference [109]. A recent study among the Chinese general population also indicates that women's blood Mn levels are about $29 \%$ higher than men's [16], consistent with reports in the literature that Korean and Italian women's Mn levels are $25 \%$ higher [111, 112] and Canadian women have about $23 \%$ higher levels [113] than the respective men's population.

Gender may also be a contributing factor to developing cardiovascular toxicity after Mn exposure. In a study of male and female smelters exposed to $\mathrm{Mn}$, female smelters had significantly shorter P-R intervals compared to controls, and there was no difference in males. QRS and T waves were also significantly different for female smelters [68]. Ethnicity could potentially be a factor that could influence susceptibility to Mn toxicity. In the 2011-2012 NHANES, the Asian population tended to accumulate significantly more $\mathrm{Mn}$ than either non-Hispanic Caucasians or non-Hispanic Black individuals [109].

Individuals with pre-existing neurological disease may be at special risk of developing Mn toxicity, because of the potential for combined insults. Persons with iron deficiency are of special concern, because animal evidence indicates that gastrointestinal absorption of manganese is enhanced by iron deficiency [110].

While pregnancy is not a pre-existing condition, it is a condition during which the susceptibility to Mn toxicity may be increased. Again, the 2011-2012 NHANES demonstrates that pregnant women accumulate higher levels of Mn than do other persons [109]. In a recent study of maternal blood Mn levels and neurodevelopment of infants at 6 months of age, researchers discovered significant associations between the mother blood Mn levels and their children's scores on mental and psychomotor developmental indexes. Interestingly, both high and low Mn blood levels were associated with lower scores [114]. Maternal blood Mn levels have also been shown to be associated with inhibited enzyme activity of newborn erythrocyte Ca pump at both low and high levels of maternal Mn [115]. A study conducted among pregnant women from Paris suggests that environmental exposure to Mn may increase the risk of preeclampsia. Mn cord blood concentrations in that study were significantly higher in women with preeclampsia [116].

From a mechanistic point of view, SLC30A10, a solute carrier (family 30 and member 10), has been suggested to regulate
Mn export from the cells. This protein is highly expressed in the liver with a higher specificity for Mn than $\mathrm{Zn}$. Genetic alterations in the SLC30A10 enzyme have recently been discovered. An autosomal-recessive mutation in this transport protein leads to an inherited Mn hypermanganesemia [26, 57] and results in a pleomorphic phenotype, including dystonia and adult-onset Parkinsonism [117].

\section{Diagnosis and Clinical Intervention}

\section{Biomarkers of Mn Exposure}

In Mn occupational exposures, the symptoms often develop quickly because the exposure levels are relatively high. In comparison, symptoms resulting from environmental exposures may be much more subtle and thus difficult to detect because they develop slowly, over a lifetime. Thus, it is crucial to detect these changes with a reliable biomarker in order to prevent the irreversible damage or the loss of function resulting from $\mathrm{Mn}$ toxicity. The biomarkers associated with monitoring Mn exposure in animal and human studies are summarized in Table 2.

Blood and urine are the most commonly used biological matrices for biomonitoring. However, the poor relationships between Mn concentrations in blood and urine and the external exposure levels make it very difficult to determine the internal exposure [120, 128••]. For example, the half-life of $\mathrm{Mn}$ in blood is less than $2 \mathrm{~h}$ [129]. Plasma Mn concentrations measured during the dosing phase of a chronic Mn exposure study began to decline after 2 weeks, although Mn exposure was still ongoing [66••]. Mn can be detected in human saliva samples. Our human study on Mn-exposed welders found that changes of saliva Mn concentrations mirrored those of serum Mn levels. But, because of a fairly large variation in saliva Mn levels, the authors did not recommend to use saliva Mn to assess Mn exposure [119]. Because more than $95 \%$ of Mn is eliminated in bile to feces, urine Mn levels are expected to be very low [65]. For these reasons, we do not recommend using Mn levels in blood, urine, or saliva as the biomarkers of Mn exposure.

Attempts to identify additional non-invasive biomarkers have concluded that using hair and nail samples may be a possibility. In our own studies [7, 8], we collected hair and nail samples from smelters and control subjects. The data showed such a vast variation to the degree that we believe it would be misleading to report these data. A thorough, yet rapid process must be developed in order to eliminate the external contamination before hair and nail samples can be used in research. Regardless, studies of residents living near a ferromanganese refinery in Brazil have shown that significant correlations exist between hair and fingernail Mn levels and the performance on neuropsychological tests [130]. 
Table 2 Possible biomarkers of Mn exposure

\begin{tabular}{|c|c|c|c|c|}
\hline Potential biomarkers & Measured by & Interpretation & $\begin{array}{l}\text { Usefulness in } \\
\text { epidemiological studies }\end{array}$ & Reference(s) \\
\hline Blood (whole blood) & ICP-MS; AAS & Most commonly studied; reflects recent exposure; large variation & Limited & {$[15,118]$} \\
\hline Blood (plasma) & AAS & Short half-life may miss periods of peak exposure; large variation & No & [118] \\
\hline Blood (serum) & AAS & Low concentration; large variation & No & [119] \\
\hline Plasma $\mathrm{Mn} / \mathrm{Fe}$ ratio & AAS & Good correlation to neurobehavioral changes; limited data & Possible & {$[7,8]$} \\
\hline Erythrocyte $\mathrm{Mn} / \mathrm{Fe}$ ratio & & Same as above & Possible & {$[7,8]$} \\
\hline Mn citrate & & Difficult to measure; never tested in humans & unknown & {$[20]$} \\
\hline Urine & & No association between $\mathrm{Mn}$ inhalation and urinary Mn levels & No & {$[120,121]$} \\
\hline Saliva & ICP-MS & $\begin{array}{l}\text { Partly changes in response to airborne Mn concentrations; large } \\
\text { variation }\end{array}$ & No & [119] \\
\hline Hair & ICP-MS & $\begin{array}{l}\text { Susceptible to external contamination; cleaning methods may } \\
\text { affect accuracy of measurement }\end{array}$ & Limited & [122-124] \\
\hline Nails & ICP-MS & $\begin{array}{l}\text { Correlated with brain Mn levels; large variation; external } \\
\text { contamination issue }\end{array}$ & Possible & {$[121,125]$} \\
\hline Teeth (dentin) & ICP-MS & $\begin{array}{l}\text { Characterizes prenatal and early postnatal Mn exposure; } \\
\text { incorporated directly into developing dentin }\end{array}$ & Limited & [126] \\
\hline Teeth (enamel) & IMS & Predicts exposure & Limited & {$[127]$} \\
\hline Bone & AAS; NAA & Reflects body burden; technical possible & Yes & {$[66 \bullet \bullet$} \\
\hline Cerebrospinal fluid & AAS & Correlated with brain and bone Mn levels & Possible & {$[66 \bullet \bullet$} \\
\hline Breast milk & & & No & \\
\hline Sweat & & & No & \\
\hline
\end{tabular}

$I C P-M S$ inductively coupled plasma mass spectroscopy, $A A S$ atomic absorption spectroscopy, NAA neutron activated analysis, IMS ion mass spectrometry

Grashow and colleagues have recently suggested using toenail $\mathrm{Mn}$ concentration as a biomarker of occupational welding fume exposure [131]; their study, however, did not relate the toenail Mn level to any biological outcomes.

In a study of Mn-exposed smelters, Mn concentrations in plasma and erythrocytes were found to increase with a corresponding decrease of Fe concentrations in plasma and erythrocytes [7, 8]. Since Mn concentrations reflect the environmental exposure and $\mathrm{Fe}$ concentrations reflect a biological response to Mn exposure, combining both parameters by dividing the $\mathrm{Mn}$ concentration by the Fe concentration (i.e., $\mathrm{MnC} / \mathrm{FeC}$ ) would enlarge the difference between groups and therefore increase the sensitivity. This thought process led to the development of a concept of $\mathrm{Mn} / \mathrm{Fe}$ ratio in plasma (pMIR) or erythrocytes (eMIR) [7]. Because there is a significant correlation between pMIR and eMIR to airborne Mn concentration, both pMIR and eMIR appear to be good candidates as the biomarkers for $\mathrm{Mn}$ exposure assessment. Nonetheless, the same study also showed a better correlation between eMIR and low- or high-exposure outcomes [7]. The utility of pMIR in environmental exposure assessment requires more rigorous testing. Additionally, as Mn citrate in blood rapidly enters brain, elevated levels of plasma or serum $\mathrm{Mn}$ citrate may be a biomarker of elevated risk of Mndependent neurological disorders in occupational health [34].

A relatively long half-life (about $8-9$ years in human) of $\mathrm{Mn}$ in the skeletal system (see above) renders bone Mn concentration an ideal indicator to assess the body burden of $\mathrm{Mn}$.
The technical challenge has always been the development of equipment with appropriate sensitivity for such a purpose. The good news is that such a technology has now become a reality. In recently published manuscripts, Nie and colleagues have optimized and verified a neutron activation-based analysis (NAA) technique for non-invasive, real-time quantification of Mn concentrations in the bone. The equipment, at this writing, is compact enough to be transportable to the sites for testing human workers and subjects. The method is sensitive and can quantify Mn concentrations as low as $0.5 \mathrm{ppm}$ of $\mathrm{Mn}$ in bone $[14,132]$ and recently even lower to $0.3 \mathrm{ppm}$ (personal communication).

Another non-invasive technique that can be used to analyze $\mathrm{Mn}$ exposure in vivo is magnetic resonance imaging (MRI). $\mathrm{Mn}$ accumulation in the brain can be visualized as an increased T1-weighted hyper-intense MRI signal. By dividing the signal observed in the globus pallidus by the signal observed in the white matter in the frontal cortex and multiplying by 100 , a pallidal index (PI) can be calculated to quantify $\mathrm{Mn}$ intensity. The PI has been proven to be a reliable marker for Mn exposure [9, 61]. Workers with more than 5 years' experience showed nearly $100 \%$ occurrence of enhanced PI, suggesting that the PI is specific for Mn exposure even when no clinical symptoms are evident [61]. One downside for using MRI is that it is only good for recent exposures. In human studies of smelters or intravenous ephedrone users, the signal in the globus pallidus almost completely disappears 56 months after cessation of exposure [37, 61]. 
Magnetic resonance spectroscopy (MRS) is another useful technique to quantify neurochemical markers associated with Mn exposure [61]. Quantitation of GABA, glutamate, total creatine ( $\mathrm{tCr}$ ), and $N$-acetyl-aspartate (NAA)/tCr values, along with other macromolecules, has been made available by MRS. In the thalamus and basal ganglia of Mn-exposed smelters, levels of GABA were nearly doubled, whereas the mean airborne $\mathrm{Mn}$ level was only $0.18 \mathrm{mg} / \mathrm{m}^{3}$, which is below the occupational standard. This may indicate an early metabolic or pathological change associated with low-level Mn exposure, and MRS appears capable of detecting these biochemical changes before the full-blown symptoms become evident [9].

For animal researchers, recent advancement in the synchrotron X-ray fluorescent (XFR) imaging technique allows to visualize the concentration and distribution pattern of multiple metals in the brain. The technique can now reach the resolution down to the single-cell level [63].

\section{Clinical Intervention}

The foremost therapeutic strategy in treatment of Mn toxicity is to remove the patient from the source of the Mn exposure. If the intoxication is life threatening, the procedures to relieve the critical signs and symptoms should first be employed. For a thorough treatment, chelation therapies can help reduce the body burden of Mn, but such treatments may not be able to improve symptoms. Another possible therapy includes Fe supplementation.

Chelation of free Mn with intravenous ethylenediaminetetraacetic acid (EDTA) has been shown to increase Mn excretion in urine and decrease Mn concentrations in blood, but chelation does not significantly improve patients' clinical symptoms [6, 39]. A recent report by Tuschl et al. demonstrates that two patients with inherited hypermanganesemia who received EDTA chelation had a significantly increased urinary excretion of Mn. Whole blood Mn levels and the MRI signals in the globus pallidus were also reduced [57]. In vitro studies have documented that EDTA can effectively block toxic effects of $\mathrm{Mn}$ on mitochondrial oxygen consumption when added either before or after Mn exposure [132]. Thus, for the purpose of reducing $\mathrm{Mn}$ in the blood compartment in the initial emergency phase, EDTA has a therapeutic benefit. However, EDTA molecules are highly water soluble and poorly pass across the blood-brain barrier. The low brain bioavailability of EDTA limits its effectiveness in treatment of Mn intoxication [39].

Para-aminosalicylic acid (PAS) is an FDA-approved drug used for the treatment of tuberculosis. Studies mainly in Chinese patients show the promising effectiveness in treating severe $\mathrm{Mn}$ intoxication with promising prognosis [39]. Animal studies further verify its chelating effect in removing $\mathrm{Mn}$ from the body [133]. As a hard Lewis acid, $\mathrm{Mn}^{3+}$ can form a stable complex with hard donor atoms such as oxygen donors in PAS structure, while the $\mathrm{Mn}^{2+}$ cation prefers relatively softer donors such as nitrogen, which is also present in PAS structure. Thus, it is possible that PAS may form stable complexes with both $\mathrm{Mn}^{2+}$ and $\mathrm{Mn}^{3}$ species and remove them from where they are stored. Moreover, the salicylate structure in PAS, which has a proven anti-inflammatory effect, may contribute to the therapeutic prognosis of PAS in treatment of manganism [39, 134]. Our recent studies also demonstrated that the parent PAS was found predominantly in blood and in choroid plexus tissues, whereas its metabolite $N$-acetyl-paraaminosalicylic acid (AcPAS) was found in the brain parenchyma, cerebrospinal fluid, choroid plexus, and capillary fractions [135]. Both PAS and AcPAS were transported in the brain by the multidrug resistance-associated protein 1 (MRP1), a member of the superfamily of ATP-binding cassette (ABC) transporters. However, the removal or efflux of PAS from brain parenchyma into the blood was mediated by the multidrug resistance protein 1 (MDR1), also called Pglycoprotein [136].

One additional therapy includes Fe supplementation. In a pilot study with a sample size of one, Tuschl et al. showed that Fe supplementation, in addition to chelation therapy, led to a marked improvement of neurological symptoms, whereas the chelation therapy alone did little to improve symptoms. The authors proposed that supplementing with Fe may help reduce blood Mn levels and lower Mn body burden [57].

\section{Conclusions}

The past decade is a thriving period in the history of $\mathrm{Mn}$ research. The total volume of publications related to manganese toxicity by a PubMed search in the last 11 years is 1619 (from our last published review on 1 April 2004 to this writing on 5 April 2015), which far exceeds the cumulative numbers of 1199 published papers on Mn toxicity for the past 167 years ever since Couper [79] reported on the first case of manganism in 1837 ( to 31 March 2004). On a more fundamental level, the essence of what we consider to be a Mn exposure has undergone a significant change, from traditionally recognized occupational manganism to low-level $\mathrm{Mn}$ exposures in a variety of environmental settings, nutritional sources, contaminated foods, infant formulas, and water, soil, and air with natural or man-made contaminations. Cumulative evidence on Mn toxicities and the vast public interest in this metal speak volumes of its public health importance, calling for a thorough understanding of its risk, the mechanism of its harm, some forms of effective clinical interventions, and any applicable strategy for prevention. Thus, we predict that the research on Mn toxicity, or its nutritional benefit for that matter, is far from finished and will become even more productive in the coming decade. Several key developing areas are summarized below. 
First, individual factors such as age, gender, and ethnicity can influence an individual's susceptibility to Mn toxicity. Children's susceptibility to Mn toxicity is of utmost concern as children accumulate higher levels of $\mathrm{Mn}$ and eliminate less $\mathrm{Mn}$ than adults. The toxic exposures tend to impact academic performance and biochemical processes. More research is deemed necessary in this area.

Second, Mn neurotoxicities, once the signs and symptoms appear, are usually irreversible and actually continue to progress, despite removal from the exposure scene. A long existing challenge in the $\mathrm{Mn}$ research has always been the search for an effective biomarker that is clinically useful for diagnosis or early diagnosis of $\mathrm{Mn}$ intoxication. Understandably, without such biomarkers, however wishful one would be, the risk assessment remains a futile task. Currently, several approaches, such as using $\mathrm{Mn} / \mathrm{Fe}$ ratio, toenails, and hair, appear to be promising; yet, many of these and other approaches remain in their infancy, and more needs to be done.

Third, the recent progress in theory and technical development has made it possible for non-invasive assessment of bone $\mathrm{Mn}$ in humans. This approach is likely to generate innovative information not only for risk assessment but also for nutritional monitoring of Mn levels in children as well as adults. It is possible, and even likely, that $\mathrm{Mn}$ stored in bone may be released slowly over time and thus serves as an internal source of Mn exposure. Topics such as Mn and bone, its causes and consequences, interactions with other metals, and biochemical mechanism of its transport and storage, along with pertinent technical innovation, will become a hot area in $\mathrm{Mn}$ research.

Finally, in mechanistic investigation, recent observations of the disruptive effect of $\mathrm{Mn}$ on adult neurogenesis in both the subventricular zone and subgranular zone have identified a new direction in Mn toxicological research. Understanding how environmental exposures to toxic metals impact the proliferation, differentiation, and migration of neural stem/progenitor cells in the adult brain for neural repair and functional integrity should have profound implications not only for studying Mn neurotoxicity but also for a better grasp of other neurodegenerative diseases such as Parkinson's disease or Alzheimer's disease.

Acknowledgments This work is supported by the following grants: National Institute of Health/National Institute of Environmental Health Grants ES008146 and ES017055.

\section{Compliance with Ethics Guidelines}

Conflict of Interest The authors declare that they have no competing interests.

Human and Animal Rights and Informed Consent This article does not contain any studies with human or animal subjects performed by any of the authors.

\section{References}

Papers of particular interest, published recently, have been highlighted as:

- Of importance

- Of major importance

1. Nadaska G, Lesny J, Michalik I. Environmental aspect of manganese chemistry. 2012;1-16. http://heja.szif.hu/ENV/ENV 100702-A/env100702a.pdf

2. Aschner M, Vrana KE, Zheng W. Manganese uptake and distribution in the central nervous system (CNS). Neurotoxicology. 1999;20:173-80.

3. Post JE. Manganese oxide minerals: crystal structures and economic and environmental significance. Proc Natl Acad Sci U S A. 1999;96:3447-54.

4. Aschner M, Guilarte TR, Schneider JS, Zheng W. Manganese: recent advances in understanding its transport and neurotoxicity. Toxicol Appl Pharmacol. 2007;221:131-47.

5. Guilarte TR. Manganese and Parkinson's disease: a critical review and new findings. Environ Health Perspect. 2010;118(8):107180.

6. Crossgrove JS, Zheng W. Manganese toxicity upon overexposure. NMR Biomed. 2004;17:544-53.

7. Cowan DM, Fan Q, Zou Y, Shi X, Chen J, Aschner M, et al. Manganese exposure among smelting workers: blood manganese-iron ratio as a novel tool for manganese exposure assessment. Biomarkers. 2009;14:3-16.

8. Cowan DM, Zheng W, Zou Y, Shi X, Chen J, Rosenthal FS, et al. Manganese exposure among smelting workers: relationship between blood manganese-iron ratio and early onset neurobehavioral alterations. NeuroToxicology. 2009;30:1214-22.

9. Dydak U, Jiang YM, Long LL, Zhu H, Chen J, Li WM, et al. In vivo measurement of brain GABA concentrations by magnetic resonance spectroscopy in smelters occupationally exposed to manganese. Environ Health Perspect. 2011;2:219-24.

10. Alessio L, Apostoli P, Ferioli A, Lombardi S. Interference of manganese on neuroendocrinal system in exposed workers. Preliminary report. Biol Trace Elem Res. 1989;21:249-53.

11. Mutti A, Bergamaschi E, Alinovi R, Lucchini R, Vettori MV, Franchini I. Serum prolactin in subjects occupationally exposed to manganese. Ann Clin Lab Sci. 1996;26(1):10-7.

12. Lucchini R, Zimmerman N. Lifetime cumulative exposure as a threat for neurodegeneration: need for prevention strategies on a global scale. NeuroToxicology. 2009;30:1144-8.

13. Rahil-Khazen R, Bolann BJ, Myking A, Ulvik RJ. Multi-element analysis of trace element levels in human autopsy tissues by using inductively coupled atomic emission spectrometry technique (ICP-AES). J Trace Elem Med Biol. 2002;16(1):15-25.

14. Liu YZ, Byrne P, Wang HY, Koltick D, Zheng W, Nie L. A compact DD neutron generator-based NAA system to quantify manganese (Mn) in bone in vivo. Physiol Meas. 2014;35:1899-911.

15. ATSDR (2012). Toxicological profile for manganese. September 2012. http://www.atsdr.cdc.gov/toxprofiles/tp.asp?id=102\&tid= 23

16. Zhang LL, Lu L, Pan YJ, Ding CG, Xu DY, Huang CF, et al. Baseline blood levels of manganese, lead, cadmium, copper, and zinc in residents of Beijing suburb. Environ Res. 2015;140:10-7.

17. $\mathrm{Au} \mathrm{C}$, Benedetto A, Aschner M. Manganese transport in eukaryotes: the role of DMT1. Neurotoxicology. 2008;29:569-76.

18. Aschner M, Gannon M. Manganese (Mn) transport across the rat blood-brain barrier: saturable and transferrin-dependent transport mechanisms. Brain Res Bull. 1994;33(3):345-9. 
19. Zheng W. Blood-CSF barrier in iron regulation and manganeseinduced Parkinsonism. In: Zheng W, Chodobski A, editors. The blood-cerebrospinal barrier. New York: CRC Press; 2005. p. 413 36.

20. Crossgrove JS, Allen DD, Bukaveckas BL, Rhineheimer SS, Yokel RA. Manganese distribution across the blood-brain barrier. I. Evidence for carrier-mediated influx of manganese citrate as well as manganese and manganese transferrin. NeuroToxicology. 2003;24(1):3-13.

21. He L, Girijashanker K, Dalton TP, Reed J, Li H, Soleimani M, et al. ZIP8, member of the solute-carrier-39 (SLC39) metaltransporter family: characterization of transporter properties. Mol Pharmacol. 2006;70(1):171-80.

22. Fujishiro H, Yano Y, Takada Y, Tanihara M, Himeno S. Roles of ZIP8, ZIP14, and DMT1 in transport of cadmium and manganese in mouse kidney proximal tubule cells. Metallomics. 2012;4(7): $700-8$.

23. Lucaciu CM, Dragu C, Copaescu L, Morariu VV. Manganese transport through human erythrocyte membranes. EPR Study Biochim Biophys Acta. 1997;1328(2):90-8.

24. Kannurpatti SS, Joshi PG, Joshi NB. Calcium sequestering ability of mitochondria modulates influx of calcium through glutamate receptor channel. Neurochem Res. 2000;25(12):1527-36.

25. Crossgrove JS, Yokel RA. Manganese distribution across the blood-brain barrier. IV. Evidence for brain influx through storeoperated calcium channels. NeuroToxicology. 2005;26:297-307.

26. DeWitt MR, Chen P, Aschner M. Manganese efflux in Parkinsonism: insights from newly characterized SLC30A10 mutations. Biochem Biophys Res Commun. 2013;432(1):1-4.

27. Madejczyk MS, Ballatori N. The iron transporter ferroportin can also function as a manganese exporter. Biochim Biophys Acta. 2012;1818(3):651-7.

28. Kobayashi K, Kuroda J, Shibata N, Hasegawa T, Seko Y, Satoh M, et al. Induction of metallothionein by manganese is completely dependent on interleukin-6 production. J Pharmacol Exp Ther. 2007;320(2):721-7.

29. Wang X, Li GJ, Zheng W. Upregulation of DMT1 expression in choroidal epithelia of the blood-CSF barrier following manganese exposure in vitro. Brain Res. 2006;30:1-10.

30. Gibbons RA, Dixon SN, Hallis K, Russell AM, Sansom BF, Symonds HW. Manganese metabolism in cows and goats. Biochim Biophys Acta (BBA) Gen Subj. 1976;444(1):1-10.

31. Sheng Y, Butler GE, Schumacher M, Cascio D, Cabelli DE, Valentine JS. Six-coordinate manganese (3+) in catalysis by yeast manganese superoxide dismutase. Proc Natl Acad Sci U S A. 2012;109(36):14314-9.

32. Harris WR, Chen Y. Electron paramagnetic resonance and difference ultraviolet studies of $\mathrm{Mn} 2+$ binding to serum transferrin. J Inorg Biochem. 1994;54(1):1-19.

33. Reaney SH, Kwik-Uribe CL, Smith DR. Manganese oxidation state and its implications for toxicity. Chem Res Toxicol. 2002;15(9):1119-26.

34. Michalke B, Fernsebner K. New insights into manganese toxicity and speciation. J Trace Elem Med Biol. 2014;28:106-16.

35. Yokel RA. Manganese flux across the blood brain barrier. NeuroMolecular Med. 2009;11:297-310.

36. Chua AC, Morgan EH. Manganese metabolism is impaired in the Belgrade laboratory rat. J Comp Physiol B. 1997;167(5):361-9.

37. Sikk K, Haldre S, Aquilonius S-M, Taba P. Manganese-induced Parkinsonism due to ephedrone abuse. Parkinson's Disease. 2011;1-8

38. Leavens TL, Rao D, Anderson ME, Dorman DC. Evaluating transport of manganese from olfactory mucosa to striatum by pharmacokinetic modeling. Toxicol Sci. 2007;97:265-78.

39. Jiang YM, Mo XA, Du FQ, Fu X, Zhu XY, Gao HY, et al. Effective treatment of manganese-induced occupational parkinsonism with PAS-Na: a case of 17-year follow-up study. J Occup Environ Med. 2006;48:644-9.

40. Korczynski RE. Occupational health concerns in the welding industry. Appl Occup Environ Hyg. 2000;15:936-45.

41. Lucchini RG, Dorman DC, Elder A, Veronesi B. Neurological impacts from inhalation of pollutants and the nose-brain connection. Neuro Toxicology. 2012;33:838-41.

42. Zoni S, Bonetti G, Lucchini R. Olfactory functions at the intersection between environmental exposure to manganese and Parkinsonism. J Trace Elem Med Biol. 2012;26:179-82.

43. Kanayama Y, Tsuji T, Enomoto S, Amano R. Multitracer screening: brain delivery of trace elements by eight different administration methods. Biometals. 2005;18:553-65.

44. U.S. EPA. Manganese. EPA integrated risk information system 7439-96-5. Washington, D.C.: Environmental Protection Agency; 1995.

45. Kondakis XG, Makris N, Leotsinidis M, Prinou M, Papapetropoulos T. Possible health effects of high manganese concentration in drinking water. Arch Environ Health. 1989;44(3):175-8.

46. Frisbie SH, Ortega R, Maynard DM, Sarkar B. The concentrations of arsenic and other toxic elements in Bangladesh's drinking water. Environ Health Perspect. 2002;110(11):1147-53.

47. Khan K, Wasserman GA, Liu X, Ahmed E, Parvez F, Slavkovich $\mathrm{V}$, et al. Manganese exposure from drinking water and children's academic achievement. Neurotoxicology. 2012;33:91-7.

48. Khan K, Factor-Litvak P, Wasserman GA, Liu X, Ahmed E, Parvez F, et al. Manganese exposure from drinking water and children's classroom behavior in Bangladesh. Environ Health Perspect. 2013;119:1501-6.

49. Bouchard M, Laforest F, Vandelac L, Bellinger D, Mergler D. Hair manganese and hyperactive behaviors: pilot study of school-age children exposed through tap water. Environ Health Perspect. 2007;115:122-7.

50. Bouchard MF, Sauve S, Barbeau B, Legrand M, Brodeur ME, Bouffard T, et al. Intellectual impairment in school-age children exposed to manganese from drinking water. Environ Health Perspect. 2011;119:138-43.

51. Lucchini RG, Guazzetti S, Zoni S, Donna F, Peter S, Zacco A, et al. Tremor, olfactory and motor changes in Italian adolescents exposed to historical ferromanganese emission. NeuroToxicology. 2012;33:687-96.

52. DeSimone LA, Hamilton PA, Gilliom RJ. The quality of our nation's waters - quality of water from domestic wells in principal aquifers of the United States, 1991-2004 - overview of major findings. U.S. Geological Survey Circular 1332. 2009; p48.

53. Tran TT, Chowanadisai W, Crinella FM, Chicz-DeMet A, Lönnerdal B. Effect of high dietary manganese intake of neonatal rats on tissue mineral accumulation, striatal dopamine levels, and neurodevelopmental status. NeuroToxicology. 2002;23:635-43.

54. Stastny D, Vogel RS, Picciano MF. Manganese intake and serum manganese intake of human milk-fed and formula-fed infants. Am J Clin Nutr. 1984;39:872-8.

55. Collipp PJ, Chen SY, Maitinsky S. Manganese in infant formulas and learning disability. Ann Nutr Metab. 1983;27:488-94.

56. Aschner JL, Aschner M. Nutritional aspects of manganese homeostasis. Mol Asp Med. 2005;26:353-62.

57. Tuschl K, Mills PB, Clayton PT. Manganese and the brain. Int Rev Neurobiol. 2013;110:277-312.

58. Subramanian KS, Meranger JC. Graphite furnace atomic absorption spectrometry with nitric acid deproteinization for determination of manganese in human plasma. 1985;57(13):2478-81.

59. Krebs N, Langkammer C, Goessler W, Ropele S, Fazekas F, Yen $\mathrm{K}$, et al. Assessment of trace elements in human brain using inductively coupled plasma mass spectrometry. J Trace Elem Med Biol. 2014;28(1):1-7. 
60. Schmitt C, Strazielle N, Richaud P, Bouron A, Ghersi-Egea JF. Active transport at the blood-CSF barrier contributes to manganese influx in the brain. J Neurochem. 2011;117:747-56.

61. Jiang YM, Zheng W, Long LL, Zhao WJ, Li XG, Mo XA, et al. Brain magnetic resonance imaging and manganese concentrations in red blood cells of smelting workers: search for biomarkers of manganese exposure. NeuroToxicology. 2007;28:126-35.

62. Robison G, Zakharova T, Fu S, Jiang W, Fulper R, Barrea R, et al. $\mathrm{X}$-ray fluorescence imaging: a new tool for studying manganese neurotoxicity. PLoS ONE. 2012;7:e48899.

63. Robison G, Zakharova T, Fu S, Jiang W, Fulper R, Barrea R, et al. $\mathrm{X}$-ray fluorescence imaging of the hippocampal formation after manganese exposure. Metallomics. 2013;5:1554-65.

64. Pejovic-Milic A, Aslam, Chettle DR, Oudyk J, Pysklywec MW, Haines T. Bone manganese as a biomarker of manganese exposure: a feasibility study. Am J Ind Med. 2009;52:742-750.

65. Schroeder HA, Balassa JJ, Tipton IH. Essential trace metals in man: manganese. A study in homeostasis. J Chronic Dis. 1966;19:545-71.

66.• O’Neal S, Hong L, Fu S, Jiang W, Jones A, Nie LH, et al. Manganese accumulation in bone following chronic exposure in rats: steady-state concentration and half-life in bone. Toxicol Lett. 2014;229:90-100. A detailed report on Mn accumulation and calculation leading to define the half-life of $\mathrm{Mn}$ in bone.

67. Chen JY, Tsao G, Zhao Q, Zheng W. Differential cytotoxicity of Mn (II) and Mn (III): special reference to mitochondrial [Fe-S] containing enzymes. Toxicol Appl Pharmacol. 2001;175:160-8.

68. Jiang Y, Zheng W. Cardiovascular toxicities upon manganese exposure. Cardiovasc Toxicol. 2005;5:345-54.

69. Zheng W, Ren S, Graziano JH. Manganese inhibits mitochondrial aconitase: a mechanism of manganese neurotoxicity. Brain Res. 1998;799:334-42.

70. Morello M, Canini A, Mattioli P, Sorge RP, Alimonti A, Bocca B, et al. Sub-cellular localization of manganese in the basal ganglia of normal and manganese-treated rats an electron spectroscopy imaging and electron energy-loss spectroscopy study. NeuroToxicology. 2008;29:60-72.

71. Kalia K, Jiang W, Zheng W. Manganese accumulates primarily in nuclei of cultured brain cells. NeuroToxicology. 2008;29:466-70.

72. Klaassen CD. Biliary excretion of metals. Drug Metab Rev. 1976;5(2):165-96.

73. Zhu J, Gale EM, Atanasova I, Rietz TA, Caravan P. Hexameric Mn (II) dendrimer as MRI contrast agent. Chemistry. 2014;20: 14507-13.

74. Marchal G, Ni Y, Zhang X, Yu J, Lodemann KP, Baert AL. MnDPDP enhanced MRI in experimental bile duct obstruction. J Comput Assist Tomogr. 1993;17:290-6.

75. Bellusci M, La Barbera A, Padella F, Mancuso M, Pasquo A, Grollino MG, et al. Biodistribution and acute toxicity of a nanofluid containing manganese iron oxide nanoparticles produced by a mechanochemical process. Int J Nanomedicine. 2014;9:1919-29.

76. Omokhodion FO, Howard JM. Trace elements in the sweat of acclimatized persons. Clin Chim Acta. 1994;231(1):23-8.

77. Grunecker B, Kltwasser SF, Zappe AC, Bedenk BT, Bicker Y, Spoormaker VI, et al. Regional specificity of manganese accumulation and clearance in the mouse brain: implications for manganese-enhanced MRI. NMR Biomed. 2013;26:542-56.

78. Sengupta P. A scientific review of age determination for a laboratory rat: how old is it in comparison with human age? Biomed Int. 2011;2:81-9.

79. Couper J. On the effects of black oxide of manganese when inhaled into the lungs. Br Ann Med Pharm Vital Stat Gen Sci. 1837;1:41-2.

80. Keen CL, Lönnerdal B. Toxicity of essential and beneficial metal ions. Manganese. In: Berthon G, editor. Handbook of metal-ligand interactions in biological fluids. New York: Marcel Dekker, Inc; 1995. p. 683-8.

81. Huang CC, Chu NS, Lu CS, Wang JD, Tsai JL, Tseng JL, et al. Chronic manganese intoxication. Arch Neurol. 1989;46:1104-6.

82. Lu L, Zhang LL, Li GJ, Guo W, Liang W, Zheng W. Serum concentrations of manganese and iron as the potential biomarkers for manganese exposure in welders. NeuroToxicology. 2005;26(2):257-65.

83. Ono K, Komai K, Yamada M. Myoclonic involuntary movement associated with chronic manganese poisoning. J Neurol Sci. 2002;199:93-6.

84. Bowler RM, Gocheva V, Harris M, Ngo L, Abdelouahab N, Wilkinson J, et al. Prospective study on neurotoxic effects in manganese-exposed bridge construction welders. NeuroToxicology. 2011;32(5):596-605.

85. Wang JD, Huang CC, Hwang YH, Chiang JR, Lin JM, Chen JS Manganese induced parkinsonism: an outbreak due to an unrepaired ventilation control system in a ferromanganese smelter. Br J Ind Med. 1989;46:856-9.

86. Racette BA, Criswell SR, Lundin JI, Hobson A, Seixas N, Kotzbauer PT, et al. Increased risk of parkinsonism associated with welding exposure. NeuroToxicology. 2012;33(5):1356-61.

87. Wang DX, Zhou WM, Wang SZ, Zheng W. Occupational exposure to manganese in welders and associated neurodegenerative diseases in China. Toxicol Sci. 1998;42(suppl):24.

88. Frumkin H, Solomon G. Manganese in the U.S. gasoline supply. Am J Ind Med. 1997;31:107-15.

89. Lytle CM, Smith BN, McKinnon CZ. Manganese accumulation along Utah roadways: a possible indication of motor vehicle exhaust pollution. Sci Total Environ. 1995;162:105-9.

90. Racette BA, McGee-Minnich L, Moerlein SM, Mink JW, Videen TO, Perlmutter JS. Welding-related Parkinsonism, clinical features, treatment, and pathophysiology. Neurology. 2001;56:8-13.

91. Racette BA, Tabbal SD, Jennings D, Good L, Perlmutter JS, Evanoff B. Prevalence of Parkinsonism and relationship to exposure in a large sample of Alabama welders. Neurology. 2005;64: $230-5$.

92. Rutchik JS, Zheng W, Jiang YM, Mo XE. How does an occupational neurologist assess welders and steelworkers for a manganese-induced movement disorder? An international team's experiences in Guangxi, China, part I. J Occup Environ Med. 2012;54(11):1432-4.

93. Rutchik JS, Zheng W, Jiang YM, Mo XE. How does an occupational neurologist assess welders and steelworkers for a manganese-induced movement disorder? An international team's experiences in Guangxi, China, part II. J Occup Environ Med. 2012;54(12):1562-4.

94. Gwiazda R, Lucchini R, Smith D. Adequacy and consistency of animal studies to evaluate the neurotoxicity of chronic low-level manganese exposure in humans. J Toxicol Environ Health A. 2007;70(7):594-605.

95. Racette BA, Aschner M, Guilarte TR, Dydak U, Criswell SR, Zheng W. Pathophysiology of manganese-associated neurotoxicity. NeuroToxicology. 2012;33:881-6. A thorough review on clinical aspects of Mn neurotoxicity by prominent researchers in this field.

96. O'Neal SL, Lee J-W, Zheng W, Cannon JR. Subacute manganese exposure in rats is a neurochemical model of early manganese toxicity. NeuroToxicology. 2014;44:303-13.

97. Vorhees CV, Graham DL, Amo-Kroohs RM, Braun AA, Grace CE, Schaefer TL, et al. Effects of developmental manganese, stress, and the combination of both on monoamines, growth, and corticosterone. Toxicol Rep. 2015;1:1046-61.

98. Long Z, Li XR, Xu J, Edden RA, Qin WP, Long LL, et al. Thalamic GABA predicts fine motor performance in 
manganese-exposed smelter workers. PLoS ONE. 2014;9: e88220.

99. Pushkar Y, Robison GA, Sullivan G, Fu SX, Kohne M, Jiang W, et al. Aging results in copper accumulations in subventricular astrocytes. Aging Cell. 2013;12:823-32.

100. Fu S, O'Neal S, Hong L, Jiang W, Zheng W. Elevated adult neurogenesis in brain subventricular zone following in vivo manganese exposure: roles of copper and DMT1. Toxicol Sci. 2015;143:482-98. The first report describing roles of altered metal homeostasis in adult neurogenesis after Mn exposure.

101. Kikuchihara Y, Abe H, Tanaka T, Kato M, Wang L, Ikarashi Y, et al. Relationship between brain accumulation of manganese and aberration of hippocampal adult neurogenesis after oral exposure to manganese chloride in mice. Toxicology. 2015;331:24-34.

102. Charash B, Placek E, Sos TA, Kligfield P. Dose-related effects of manganese on the canine electrocardiogram. J Electrocardiol. 1982;15:149-52.

103. Vander EL, Colet JM, Muller RN. Spectroscopic and metabolic effects of $\mathrm{MnCl} 2$ and MnDPDP on the isolated and perfused rat heart. Investig Radiol. 1997;32:581-8.

104. Spangler AH, Spangler JG. Groundwater manganese and infant mortality rate by county in North Carolina: an ecological analysis. EcoHealth. 2009;6:596-600.

105. Hafeman D, Factor-Litvak P, Cheng Z, van Geen A, Ahsan H. Association between manganese exposure through drinking water and infant mortality in Bangladesh. Environ Health Perspect. 2007;115(7):1107-12.

106. Long LL, Li XR, Huang ZK, Jian YM, Fu SX, Zheng W. Relationship between changes in brain MRI and 1H-MRS, severity of chronic liver damage, and recovery after liver transplantation. Exp Biol Med. 2009;234:1075-85.

107. Squitti R, Gorgone G, Panetta V, Lucchini R, Bucossi S, Albini E, et al. Implications of metal exposure and liver function in Parkinsonian patients resident in the vicinities of ferroalloy plants. J Neural Transm. 2009;116:1281-7.

108. Cahill DF, Bercegeay MS, Haggerty RC, Gerding JE, Gray LE. Age-related retention and distribution of ingested $\mathrm{Mn} 3 \mathrm{O} 4$ in the rat. Toxicol Appl Pharmacol. 1980;53:83-91.

109. Oulhote Y, Mergler D, Bouchard MF. Sex- and age-differences in blood manganese levels in the U.S. general population: national health and nutritional examination survey 2011-2012. Environ Health. 2014;13:87.

110. Mena I, Horiuchi K, Burke K, Cotzias GC. Chronic manganese poisoning. Individual susceptibility and absorption of iron. Neurology. 1969;19:1000-6.

111. Lee JW, Lee CK, Moon CS, Choi IJ, Lee KJ, Yi SM, et al. Korea national survey for environmental pollutants in the human body 2008: heavy metals in the blood or urine of the Korean population. Int J Hyg Environ Health. 2012;215:449-57.

112. Bocca B, Madeddu R, Asara Y, Tolu P, Marchal JA, Forte G. Assessment of reference ranges for blood $\mathrm{Cu}, \mathrm{Mn}, \mathrm{Se}$ and $\mathrm{Zn}$ in a selected Italian population. J Trace Elem Med Biol. 2011;25:1926.

113. Clark NA, Teschke K, Rideout K, Copes R. Trace element levels in adults from the west coast of Canada and associations with age, gender, diet, activities, and levels of other trace elements. Chemosphere. 2007;70:155-64.

114. Chung SE, Cheong HK, Ha EH, Kim BN, Ha M, Kim Y, Hong YC, Park H, Oh SY. Maternal blood manganese and early neurodevelopment: the mothers and children's environmental health (MOCEH) study. Environ Health Perspect. 2015.

115. Yazbeck C, Moreau T, Sahuquillo J, Takser L, Huel G. Effect of maternal manganese blood levels on erythrocyte calcium-pump activity in newborns. Sci Total Environ. 2006;354:28-34.
116. Vigeh M, Yokoyama K, Ramezanzadeh F, Dahaghin M, Sakai T, Morita Y, et al. Lead and other trace metals in preeclampsia: a case-control study in Tehran. Iran Environ Res. 2006;100:268-75.

117. Leyva-Illades D, Chen P, Zogzas CE, Hutchens S, Mercado JM, Swaim CD, et al. SLC30A10 is a cell surface-localized manganese efflux transporter, and parkinsonism-causing mutations block its intracellular trafficking and efflux activity. J Neurosci. 2014;34(42):14079-95.

118. Baker MG, Simpson CD, Sheppard L, Stover B, Morton J, Cocker $\mathrm{J}$, et al. Variance components of short-term biomarkers of manganese exposure in an inception cohort of welding trainees. J Trace Elem Med Biol. 2015;29:123-9.

119. Wang DX, Du XQ, Zheng W. Alteration of saliva and serum concentrations of manganese, copper, zinc, cadmium and lead among career welders. Toxicol Lett. 2008;176:40-7.

120. Smith D, Gwiazda R, Bowler R, Roels H, Park R, Taicher C, et al. Biomarkers of Mn exposure in humans. Am J Ind Med. 2007;50: 801-11.

121. Laohaudomchok W, Lin X, Herrick RF, Fang SC, Cavallari JM, Christiani DC, et al. Toenail, blood and urine as biomarkers of manganese exposure. J Occup Environ Med. 2011;53(5):506-10.

122. Riojas-Rodriguez H, Solis-Vivanco R, Schilmann A, Montes S, Rodriguez S, Rios C, et al. Intellectual function in Mexican children living in a mining area and environmentally exposed to manganese. Environ Health Perspect. 2010;118(10):1465-70.

123. Menezes-Filho JA, Paes CR, Pontes AM, Moreira JC, Sarcinelli PN, Mergler D. High levels of hair manganese in children living in the vicinity of a ferro-manganese alloy production plant. Neurotoxicology. 2009;30(6):1207-13.

124. Eastman RR, Jursa TP, Benedetti C, Lucchini RG, Smith DR. Hair as a biomarker of environmental manganese exposure. Environ Sci Technol. 2013;47(3):1629-37.

125. Sriram K, Lin GX, Jefferson AM, Roberts JR, Andrews RN, Kashon ML, et al. Manganese accumulation in nail clippings as a biomarker of welding fume exposure and neurotoxicity. Toxicology. 2012;291(1-3):73-82.

126. Arora M, Bradman A, Austin C, Vedar M, Holland N, Eskenazi B, et al. Determining fetal manganese exposure from mantle dentine of deciduous teeth. Environ Sci Technol. 2012;46(9):5118-25.

127. Ericson JE, Crinella FM, Clarke-Stewart KA, Allhusen VD, Chan T, Robertson RT. Prenatal manganese levels linked to childhood behavioral disinhibition. Neurotoxicol Teratol. 2007;29(2):181-7.

128.• Zheng W, Fu SX, Dydak U, Cowan DM. Biomarkers of manganese intoxication. NeuroToxicology. 2011;32(1):1-8. A thorough review on existing and proposed biomarkers of Mn intoxication.

129. Zheng W, Kim H, Zhao Q. Comparative toxicokinetics of manganese chloride and methylcyclopentadienyl manganese tricarbonyl in male Sprague-Dawley rats. Toxicol Sci. 2000;54:295-301.

130. Viana GF, de Carvalho CF, Nunes LS, Rodrigues JL, Ribeiro NS, de Almeida DA, et al. Noninvasive biomarkers of manganese exposure and neuropsychological effects in environmentally exposed adults in Brazil. Toxicol Lett. 2014;231(2):169-78.

131. Grashow R, Zhang J, Fang SC, Weisskopf MG, Christiani DC, Cavallari JM. Toenail metal concentration as a biomarker of occupational welding fume exposure. J Occup Environ Hyg. 2014;11(6):397-405.

132. Liu Y, Koltic D, Byrne P, Wang H, Zheng W, Nie LH. Development of a transportable neutron activation analysis system to quantify manganese in bone in vivo: feasibility and methodology. Physiol Meas. 2013;34:1593-609.

133. Zheng W, Jiang YM, Zhang YS, Jiang W, Wang X, Cowan DM. Chelation therapy of manganese intoxication by paraaminosalicylic acid (PAS) in Sprague-Dawley rats. NeuroToxicology. 2009;30:240-8. 
134. Yoon H, Kim DS, Lee GH, Kim JY, Kim DH, Kim KW, et al. Protective effects of sodium para-amino salicylate on manganeseinduced neuronal death: the involvement of reactive oxygen species. J Pharm Pharmacol. 2009;61:1563-9.

135. Hong L, Jiang W, Zheng W, Zeng S. HPLC analysis of paraaminosalicylic acid and its metabolite in plasma, cerebrospinal fluid and brain tissues. J Pharm Biomed Anal. 2011;54:1101-9.

136. Hong L, Xu C, O’Neal S, Bi HC, Huang M, Zheng W, et al. Roles of $\mathrm{P}$-glycoprotein and multidrug resistance protein in transporting para-aminosalicylic acid and its $\mathrm{N}$-acetylated metabolite in mice brain. Acta Pharmacol Sin. 2014;35(12):1577-85. 